\title{
Editorial
}

\section{Enjoy the new, remember the old}

\author{
Journal of Direct, Data and Digital Marketing Practice (2013) 14, 185-186. \\ doi:10.1057/dddmp.2013.13
}

In the fast-changing marketing environment, it is always tempting to adopt the latest techniques and channels over existing, more established ones. New is, after all, one of the most powerful words used by marketers to change the behaviour of customers and prospects - practitioners themselves are as seduced by its appeal as anybody else.

Threaded through a number of the articles in this issue of the Journal, you will find strong arguments to resist this temptation, however, not to stop trialling what is new and exciting, but to retain those options that are proven and can be counted on to deliver. Andrea Micheaux's whitepaper, 'Getting to the bottom of Pandora's box', provides a perfect example of how marketers can get carried away with a new approach and end up getting it wrong. In the pursuit of CRM, the focus should have been on what worked for the customer, but ended up being too much about what was good for the company.

Just how often CRM projects failed to deliver is now well known, the lessons that Micheaux offers need to be learned in order to avoid repeating the same mistakes in other areas. Reviewing the book, 'In Data We Trust', I was struck by the way the authors use the CRM hype cycle as a warning to companies not to repeat the same thing when becoming data-centric. The good thing is that the shift towards data may offer a way to recover the lost value of CRM by enabling customer insight at the heart of the business - exactly what did not happen the first time around.

We all like to think that experience makes us smarter and we do not repeat our mistakes. However, pressure to deliver within tight deadlines and with constrained resources is not the best classroom. As a result, marketing can easily be drawn towards the areas it feels comfortable with and away from those where it needs to improve. Only through an audit of those capabilities is a clear picture likely to emerge of whether the function is as good at its job as it imagines, something that Serge Milbank considers in detail in his article. Surprisingly, the overall score for marketing capabilities, based on dozens of audits his company has already carried out, is strictly average for every area in which marketing is performing really well, it has other black spots.

It is just as tempting to assume that resources that marketing has relied on in the past will still be there when we decide to return to them, even if we have not been making use of them recently. Geo-demographics are a good example of this. Many digital marketers only know the power of behavioural targeting and are fully focused on in-the-moment conversion or real-time lead generation. Considering what longer-term opportunities might exist or how external factors affect the profile of the customers they are acquiring may not come into it.

As a result, worrying about how the next Census will be carried out is probably not high on the digital marketing agenda. Yet, the information generated about the entire population every 10 years remains of enormous value precisely because of its reach and consistency. In discussing the options for how Census 2021 might be carried out, Barry Leventhal provides a timely reminder that without it, geo-demographic systems would be that bit less predictive and informative. That is something you might not miss until it is gone.

What you can't miss at the moment is the sheer, dynamic excitement of marketing across social networks. Not for a generation has there been such a potent new channel and never before has there been such transparency about how marketing inputs generate consumer response. Some of that can 


\section{桨 Editorial}

be on the downside - Eleanora Pantaro's whitepaper about the impact of negative comments on social networks is interesting for what it reveals about how marketers themselves deal with complaints and criticism. The more involved and social they become, the better equipped they are to deal with the negative. Venting by consumers is not going to go away - ways to deal with it better are therefore urgently required.

However, what most digital marketers get excited about is seeing their ideas take off online. Moreover, the IRN-BRU case study offers a tremendous example of just that, including some compelling data visualizations, which offer a unique insight into what going viral really means. In fact, it is a perfect combination of direct, data and digital marketing! 